\title{
Tablet Properties
}

National Cancer Institute

\section{Source}

National Cancer Institute. Tablet Properties. NCI Thesaurus. Code C134265.

Characteristics of a tablet, which include weight, length, thickness, diameter, color and shape. 